\title{
CONDICÕES HIGIÊNICO-SANITÁRIAS DAS CRECHES PÚBLICAS MUNICIPAIS DE PICOS, PIAUÍ
}

\author{
Cristina Maria de Carvalho MADEIRA ${ }^{1}$ \\ Ana Cibele Pereira SOUSA ${ }^{1 *}$ \\ Paula Adrianne Braga de SOUSA ${ }^{2}$ \\ Amanda Mazza Cruz de OLIVEIRA ${ }^{3}$ \\ Camilla Carvalho MENEZES ${ }^{3}$ \\ Stella Regina Arcanjo MEDEIROS ${ }^{3}$
}

\footnotetext{
${ }^{1}$ Nutricionista. Universidade Federal do Piauí, Campus Senador Helvídio Nunes de Barros, (UFPI).

${ }^{2}$ Vigilância Sanitária Municipal de Fortaleza.

${ }^{3}$ Professora, Doutora. Departamento de Nutrição, Campus Senador Helvídio Nunes de Barros. Universidade Federal do Piauí (UFPI) *E-mail:cibelepsousa@ hotmail.com
}

Recebido em: 03/10/2014 - Aprovado em: 01/12/2014 - Disponibilizado em: 15/12/2014

\begin{abstract}
RESUMO: Este trabalho teve como objetivo avaliar as condições higiênico-sanitárias nas creches públicas municipais de Picos - PI. Os dados foram coletados nas seis creches existentes na área urbana do município, por meio da aplicação da lista de verificação das Boas Praticas de Serviços de Alimentação, recomendada pela RDC 216/04. De acordo com percentual de itens atendidos, verificou-se que apenas a creche B foi classificada como estabelecimento de médio risco sanitário e que as demais creches avaliadas foram classificadas como estabelecimento de alto risco sanitário. As principais não conformidades que contribuíram para este panorama sanitário insatisfatório das creches estão relacionados às edificações e instalações, manejo dos resíduos, matérias-primas e manipuladores. Conclui-se que as condições inadequadas de funcionamento da maioria das creches públicas avaliadas, colocam em risco a saúde da população assistida. Portanto, faz-se necessário o planejamento de ações corretivas a curto e longo prazo entre os órgãos competentes para adequação das não conformidades e consequente oferta de alimentos íntegros e saudáveis.
\end{abstract}

Palavras-chave: Creches. Boas práticas de fabricação. Manipulação dos alimentos. Risco sanitário. Crianças.

\section{HYGIENIC-SANITARY CONDITIONS IN PUBLIC DYCARE CENTERS OF PICOS, PIAUÍ}

\begin{abstract}
This study aimed to assess the sanitary conditions in kindergartens on municipal Picos - PI. Data were collected in six existing kindergartens in urban area, through the application of the checklist of Best Practice Food Services, recommended by the RDC 216/04. According percentage of treated items, it was found that only the nursery B was classified as property medium health risk and other nurseries evaluated was classified as a high health risk. Major nonconformities who contributed to this unsatisfactory health situation of child care are related to buildings and facilities, waste management, raw materials and handlers. It is concluded that inadequate functioning of most valued public kindergartens, put the health of the assisted population at risk. Therefore, it is necessary to plan corrective actions in the short and long term between the competent bodies for adequacy of nonconformities and subsequent supply of whole and healthy foods.
\end{abstract}

Keywords: Nurseries. Good manufacturing practices. Food handling. Health risk. Children.

Introdução

É crescente o número de crianças matriculadas em creches em todos o país, com uma evolução de $72,8 \%$, passando de 1.579.581 alunos matriculados para 2.730.119 no período compreendido entre 2007 a 2013 (INEP, 2014). 
Cabe ao Estado o dever do atendimento em creches e pré-escola a crianças de zero a seis anos de idade, tendo a creche função eminentemente educativa, a qual se agrega as funções de cuidado (BRASIL, 1998).

Segundo Kappel, Carvalho e Kramer (2001) e Turatti, Pessolato e Silva (2011), além da garantia do atendimento nutricional, de saúde e de segurança, as relações interpessoais que ocorrem neste ambiente oferecerão estímulos base que influenciarão a estruturação tanto da cognição como do afeto nas fases iniciais de educação.

Uma das responsabilidades da creche é a alimentação, pois $\mathrm{o}$ ato de alimentar adequadamente uma criança permite a ela se desenvolver com saúde intelectual e física, diminuindo, ou evitando, também, o aparecimento de distúrbios e deficiências nutricionais (FAÇANHA et al., 2003).

No entanto os programas de alimentação escolar oferecem riscos, devido à possibilidade de contaminação pelo desenvolvimento bacteriano em alimentos e pelo grande número de refeições produzidas. A legislação brasileira não prevê normas específicas para o funcionamento de cozinhas em creches ou instituição de ensino (OLIVEIRA; BRASIL; TADEI, 2005).

Em virtude disso, é usada a Resolução RDC no 216 da ANVISA que se aplica a todos os serviços de alimentação que realizem atividades de manipulação, preparação, funcionamento, distribuição e venda de alimentos preparados (BRASIL, 2004).

A produção de alimentos com segurança exige cuidados essenciais para que se eliminem quase na sua totalidade os riscos de contaminação a que esses alimentos estão sujeitos, sobretudo nas etapas de manipulação e preparo da merenda escolar ofertada às crianças, considerada como grupo populacional vulnerável ou mais exposta. Neste sentido, faz-se necessário a realização desse estudo, pois através do diagnóstico das condições higiênico-sanitárias das creches pode-se orientar a tomada de ações corretivas ou fazer intervenção junto a órgãos competentes ou na oferta de serviços como consultoria para adequações cabíveis. O presente trabalho teve como objetivo avaliar as condições higiênico-sanitárias nas creches públicas no município de Picos - PI.

\section{Métodos}

O presente estudo foi realizado nas seis creches públicas municipais situadas na zona urbana de Picos - PI, referenciadas como instituições A, B, C, D, E, F e caracterizou-se como transversal, observacional e descritivo.

O estudo baseou-se na aplicação de uma lista de verificação ("CheckList"), elaborada a partir da legislação RDC 216, de 15 de setembro de 2004. Todos os quesitos 
exigidos pela legislação, quanto à preparação e manipulação segura dos alimentos, foram analisados baseados nas diretrizes das Boas Práticas de Fabricação - BPF que envolvem: Recursos Humanos, Condições Ambientais, Instalações e Edificações, Equipamentos, Higienização das Instalações, Produção, Fornecedores e Documentação (BRASIL, 2002). A lista consta de 12 blocos divididos em 89 itens.

Para a classificação das instituições foram atribuídos pontos às diferentes respostas $(\mathrm{SIM}=1$ e NÃO $=0)$. O número de respostas NÃO APLICÁVEIS (NA), observado em cada instituição, foram diminuídas do total de itens, não sendo, portanto, computados na soma final. Para obter o percentual de atendimento, de cada instituição, foi utilizada a seguinte fórmula: $\%$ de Atendimento $=$ Total de SIM $\times 100$

Total de itens - Itens NA

O panorama sanitário das instituições estudadas foi obtido de acordo o item Classificação do Estabelecimento disposto na RDC no 275 de 2002 da ANVISA (BASTOS, 2008). que de acordo com o percentual de atendimento, os estabelecimentos são classificadas em 3 grupos: Grupo 1: instituições que atendem mais de $75 \%$ dos quesitos da lista denominada de baixo risco; Grupo 2: compreende os estabelecimentos que apresentam de $51 \%$ a $75 \%$ de atendimento, consideradas com risco intermediário; e Grupo 3: que atenderam 50\% ou menos dos quesitos verificados e são identificadas como estabelecimentos de alto risco. Esta classificação serve como critério para definição e priorização das estratégias de intervenção.

Os dados foram tabulados e as análises de frequência foram realizadas com o auxílio do programa Microsoft Office Excel, versão 2003.

\section{Resultados}

A Figura 1 descreve o panorama sanitário das creches avaliadas.

Figura 1 - Percentual de adequação da lista de verificação das Boas Práticas de Serviços de Alimentação, segundo RDC 216 de 15 de setembro 2004, das creches públicas de Picos - PI, 2012.

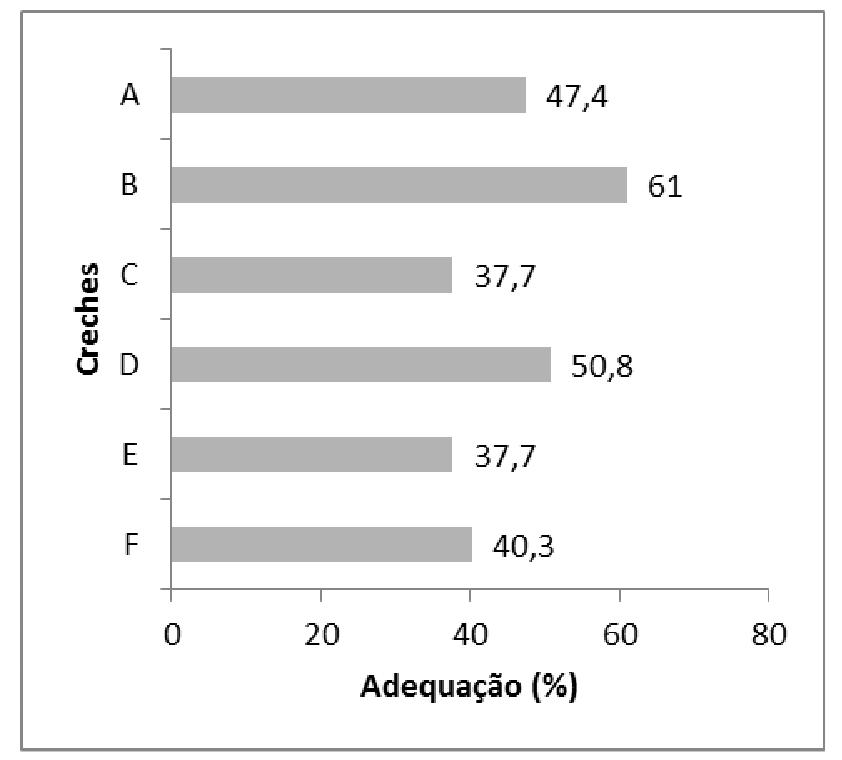

Fonte: Os autores.

De acordo com percentual de itens atendidos, verificou-se que apenas a creche B foi classificada como estabelecimento de médio risco sanitário, atingindo valores de $61 \%$ de adequação da lista de verificação das $\mathrm{BPF}$ e as demais foram classificadas como 
estabelecimentos de alto risco sanitário, demonstrando não estarem aptas a exercerem suas atividades, consequentemente, não oferecem segurança e nem qualidade das refeições produzidas.

Os resultados dos percentuais de atendimento aos itens relacionados às condições das Edificações e Instalações das creches (Figura 2) mostram que 100\% das creches avaliadas apresentaram valores inferiores a $36 \%$ de adequação.

Figura 2 - Adequação em relação ao bloco Edificações, instalações, equipamentos, móveis e utensílios das creches públicas de Picos - PI, 2012.

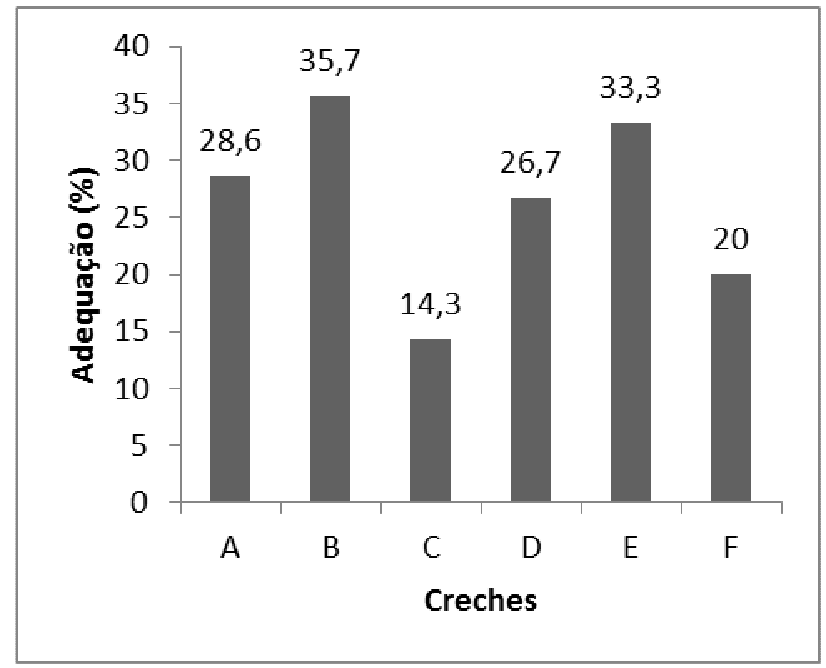

Fonte: Os autores.

Constatou-se que as principais não conformidades diagnosticadas foram: incompatibilidade do dimensionamento da edificação e instalações para a realização de todas as operações inadequação dos revestimentos e materiais utilizados nos pisos, paredes e tetos.

Em relação ao piso observou-se que em $64,7 \%$ dos estabelecimentos tinham a cor escura e em $16,7 \%$ o revestimento do piso era de cimento grosso, assim como os dados por
Veiga et al. (2006), ao estudar estabelecimentos comerciais de manipulação de alimentos, no município de Maringá (PR), nos quais se constatou precárias condições de conservação relacionadas a piso, paredes e teto. Cabe ressaltar que a legislação vigente estabelece que o piso, parede e teto devem possuir revestimento liso, impermeável, livre de rachaduras, goteiras, vazamento, bolores, descascamentos que possam favorecer a veiculação de contaminantes ao alimento (BRASIL, 2004).

Nenhuma das seis creches avaliadas possuía proteção completa contra a entrada de pragas (telas, proteção na parte inferior de portas). A legislação prevê o uso de telas milimétricas para impedir o acesso de vetores e pragas urbanas (BRASIL, 2004). No entanto, são ausentes nas aberturas da área de preparação de alimentos em todas as creches avaliadas. Observou-se que apenas na creche B o controle de vetores e pragas não era realizado por empresa especializada.

Quanto ao quesito iluminação, também foi constatada a ausência de lâmpadas com proteção em todas das creches avaliadas. Segundo recomendações, estas devem estar protegidas para evitar a contaminação do alimento em caso de quebras e as instalações elétricas devem ser seguras (ICMSF, 1991).

Os resultados referentes à Higienização de Edificações, instalações, 
equipamentos, móveis e utensílios estão apresentados na Figura 3.

Figura 3 - Adequação em relação em relação ao bloco Higienização de Edificações, instalações, equipamentos, móveis e utensílios de creches públicas de

Picos-PI,

2012.

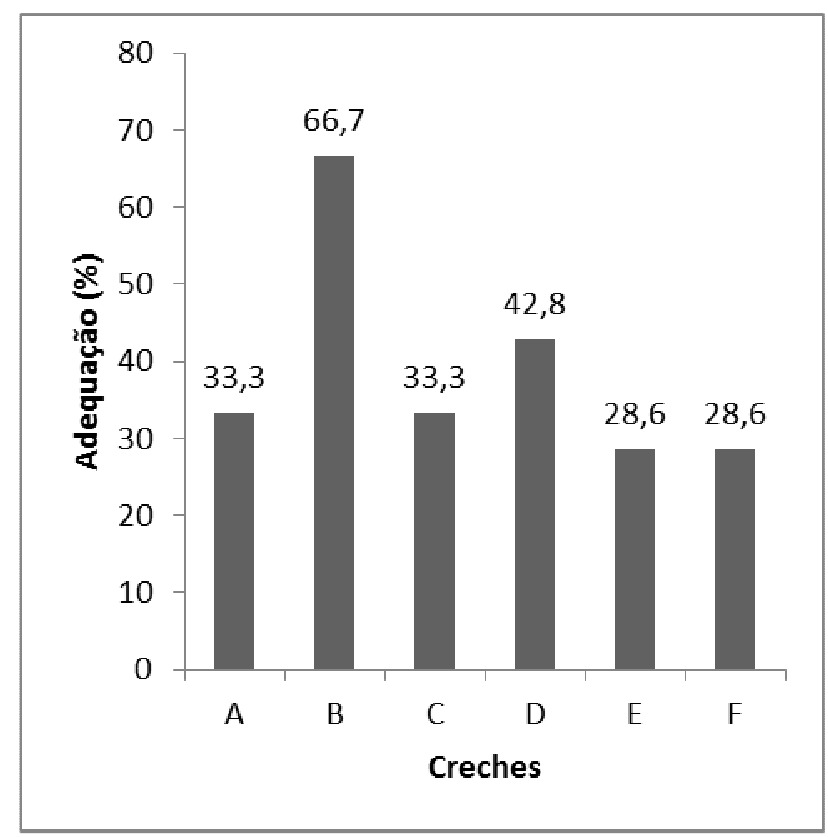

Fonte: Os autores.

As instituições $\mathrm{A}, \mathrm{C}, \mathrm{D}, \mathrm{E}$ e $\mathrm{F}$ apresentaram percentuais menores que $50 \%$ de atendimento. Diferentemente das demais creches, a instituição B apresentou percentual superior a $60 \%$ de atendimento. As principais irregularidades encontradas estavam relacionadas às operações de higienização.

Com relação ao Controle integrado de vetores e pragas, destaca-se que as creches $\mathrm{A}$, C, D, E e F apresentaram índices de conformidade à lista de verificação superiores a $60 \%$, enquanto que a creche $\mathrm{B}$ demonstrou $50 \%$ de atendimento.

Nas creches em estudo, não foi observada a existência de banheiro e de lavatórios para higienização das mãos de forma exclusiva para os manipuladores de alimentos. Além disso, as pias existentes de uso comum não possuíam todos os produtos necessários à higienização das mãos (sabonete líquido, papel toalha e anti-séptico). Dados similares foram encontrados por Rossi (2006), na avaliação de restaurantes do tipo self service de Belo Horizonte, nos quais somente $3,3 \%$ dos restaurantes ofereciam condições adequadas para a higienização das mãos.

Segundo Góes et al. (2004), a limpeza e desinfecção são operações fundamentais, embora muitas vezes feitas de forma inadequada, propiciando o desenvolvimento de microrganismos e apresentando um grande potencial da contaminação. No entanto, as operações de Higienização de Edificações, instalações, equipamentos, móveis e utensílios das creches não eram realizadas por funcionários comprovadamente capacitados, e quando não eram feitas a operação de limpeza e desinfecção das instalações e equipamentos, não havia comprovação de registrado destas atividades.

As não conformidades prevalentes nas instituições estudadas em relação ao Manejo de resíduos foram presença de recipientes de difícil higienização creches B, C, E e F, o que possibilita o acúmulo de sujidades, e a ausência em todas as unidades de coletores dotados de tampas acionadas sem contato manual.

$$
\text { Resultados similares foram }
$$
encontrados por Cardoso et al. (2005) que, avaliando cozinhas institucionais, observaram 
adequações inferiores a $50 \%$ no quesito presença de lixeiras com tampas. Essa deficiência também foi observada por Valejo et al. (2003), ao inspecionarem 52 estabelecimentos alimentícios na cidade de Presidente Prudente/SP, onde constataram a ausência de tampas nas lixeiras em $31 \%$ dos estabelecimentos.

Todas as creches tiveram apenas 50\% de adequação em relação ao Abastecimento de água. As mesmas utilizavam água tratada, visto que o sistema de abastecimento de água de todas as instituições era realizado pela rede pública. Porém, as mesmas não possuíam registros dos procedimentos operacionais de higienização dos reservatórios de água.

A Figura 4 mostra o percentual de atendimento das creches quanto aos aspectos pertinentes aos Manipuladores.

Figura 4 - Adequação em relação ao bloco Manipuladores das creches públicas de Picos - PI, 2012

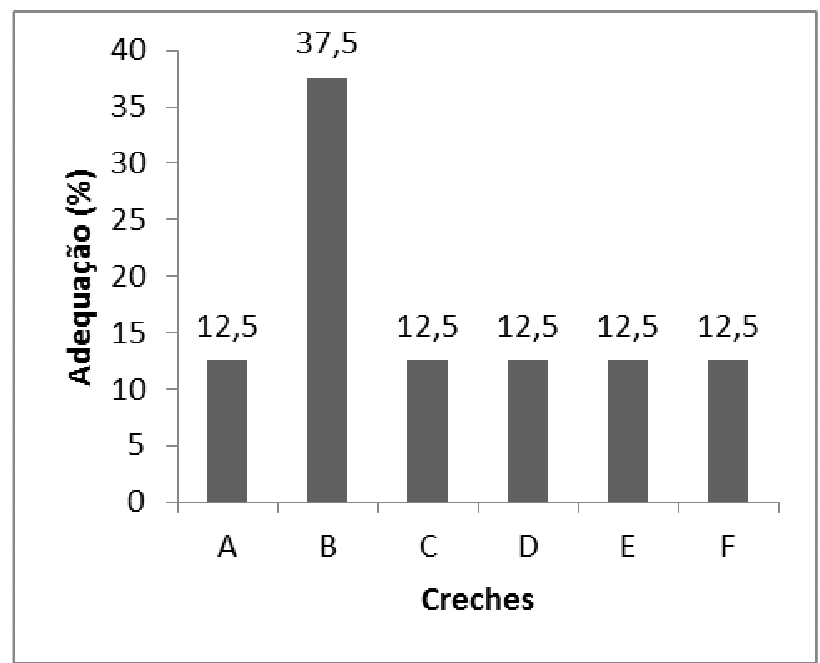

Fonte: Os autores.

As principais deficiências encontradas estavam relacionadas ao controle da saúde dos manipuladores, pois não era realizado nas seis creches visitadas, bem como os manipuladores que apresentassem lesões e ou sintomas de enfermidades que pudessem comprometer a qualidade higiênico-sanitária dos alimentos não eram afastados de suas atividades. Em 83,3\% das instituições avaliadas, os manipuladores estavam sem proteção nos cabelos, com adornos, esmalte nas unhas, com uniformes incompletos e inadequados. E, somente na creche B eles tinham o hábito de utilizar toucas descartáveis fornecidas pela Secretaria Municipal de Educação do município.

As principais deficiências encontradas com relação aos manipuladores estavam relacionadas ao controle da saúde dos mesmos e ao uso de proteção individual, pois apresentavam-se sem proteção nos cabelos, com adornos, esmalte nas unhas, e com uniformes incompletos e inadequados, assim como foi constatado por Nezi (2008), ao avaliar a aplicação dos Procedimentos Operacionais Padronizados - POP's em uma UAN de um frigorífico na cidade de Cascavel (PR), E Genta et al. (2005), os quais observaram, em seu estudo que os restaurantes do tipo self-service de Maringá, que as principais não conformidades eram: uso de aventais de material inadequado à atividade; inexistência de treinamento contínuo em higiene e manipulação de alimentos; ausência de orientação para técnica correta de higienização de mãos e uso de adornos. 
Sabe-se que os manipuladores desempenham um papel de grande importância para a sanidade dos produtos alimentícios. A lavagem das mãos e outros procedimentos de responsabilidade destes profissionais são primordiais à contribuição das boas práticas no preparo de alimentos e garantia de qualidade, sem comprometimento da saúde do consumidor (OLIVEIRA et al., 2005). Entretanto, no presente estudo, verificou-se também a ausência de cartazes orientando a lavagem correta das mãos nas seis creches avaliadas. Dados similares foram relatados por Rocha et al (2010), constatando que apenas $5,9 \%$ dos restaurantes comerciais do tipo self-service avaliados, no município de Patos de Minas(MG), possuía avisos sobre o correto procedimento de lavagem das mãos nas instalações sanitárias e na área de produção dos alimentos. Bem como não havia o controle de entrada de pessoas na cozinha em nenhuma das creches avaliadas. Segundo Andrade (2009), a cozinha deve ser frequentada apenas pelos funcionários do setor devidamente uniformizados, pois esse fluxo de pessoas inadequado proporciona aumento de riscos de contaminação microbiológica.

Em relação aos cuidados com as Matérias-primas, ingredientes e embalagens, as creches $\mathrm{A}$ e $\mathrm{B}$ apresentaram o maior percentual de atendimento às normas descritas pela legislação $(75 \%)$. A creche $\mathrm{D}$ atingiu $50 \%$ de atendimento dos quesitos e nas instituições $\mathrm{E}$ e $\mathrm{F}$ verificou-se um índice de atendimento inferior a 50\%. Ressalta-se que a creche C não atendeu a nenhum dos itens avaliados. Nesse local, o armazenamento dos ingredientes de forma desorganizada e em paletes de madeira. Uma das principais irregularidades encontradas foi a não devolução das matérias-primas, ingredientes e embalagens quando encontravam-se vencidas, mas sim jogadas no lixo (creches C, D e E). As demais relataram levar o alimento à Secretaria de Educação, onde registravam a ocorrência e solicitava medidas cabíveis.

Em $66,7 \%$ das instituições os funcionários responsáveis pelo recebimento das matérias-primas avaliavam as condições de embalagem, validade, rotulagem e qualidade das mesmas no ato da entrega.

Em relação à Exposição ao consumo do alimento preparado, a creche $\mathrm{E}$ foi a que apresentou menor índice de conformidade (25\%). Uma das irregularidades encontradas foi o armazenamento inadequado dos utensílios, pois não eram guardados em local fechado e protegido.

Observou-se em todas as creches a utilização de utensílios inadequados como tábuas de plástico para corte, e em 66,7\% é prática comum o descongelamento da carne em condições inadequadas (submersa em água a temperatura ambiente). Dados semelhantes foram observados por Lima (2001), onde em 50\% das escolas estudadas, as merendeiras não faziam o descongelamento 
correto (sob refrigeração) devido á ausência de equipamento adequado ou por ser mais fácil e demanda menor tempo. No entanto, irá comprometer a segurança alimentar pela vulnerabilidade a contaminação por multiplicação dos microrganismos quando a peça fica exposta na zona de perigo que vai de $4^{\circ} \mathrm{C}$ a $60^{\circ} \mathrm{C}$.

$$
\text { No que diz respeito à }
$$

Responsabilidade pelo serviço, evidenciou-se que o responsável pelas atividades de manipulação de todas as creches avaliadas não recebia capacitação sobre os temas: Contaminantes alimentares, Doenças transmitidas por alimentos, Boas Práticas. Eles recebiam, somente, cursos sobre reaproveitamento de alimentos e higiene.

A importância do treinamento é dar aos manipuladores conhecimentos necessários ao desenvolvimento de habilidades e atividades para capacitá-los ao trabalho (GRAMULHA, et al., 2006). Sendo que estes podem ser responsáveis diretos ou indiretos pela contaminação dos alimentos. Assim, deve-se estabelecer Procedimentos Operacionais Padronizados - POP's, realizar campanhas educativas destinadas aos funcionários, aumentar a capacitação técnica e profissional do proprietário e manipuladores de alimentos para que possam contribuir positivamente para melhoria na qualidade da segurança alimentar (OLIVEIRA, et al., 2004; SOUZA, 2006).
Ressalta-se que Nenhuma creche possuía o Manual de Boas Práticas. Não foram encontrados registros e documentação das informações colhidas em nenhuma instituição. Dados semelhantes foram encontrados por Seixas et al. (2008), ao diagnosticar BPF em estabelecimentos produtores de alimentos, constatou que $60 \%$ dos estabelecimentos não possuíam esta ferramenta e quando existia, na grande maioria, ficava em poder do proprietário ou gerente, impedindo o acesso pelos funcionários.

De acordo com Silva JR (2005), as BPF definem parâmetros de qualidade e segurança, com a regulamentação de procedimentos que obedeçam a parâmetros definidos, baseados no sistema Análise de Perigos e Pontos Críticos de Controle (APPCC). A avaliação dos documentos abrange a implantação do MBP e POP's, sendo o MBP conceituado pela ANVISA(2004) como um documento que descreve as operações realizadas pelo estabelecimento, e de obrigatoriedade para quaisquer estabelecimentos que trabalhem com a produção de alimentos.

\section{Conclusões}

A instituição B foi classificada como estabelecimento de médio risco sanitário e as demais creches avaliadas foram classificadas como estabelecimento de alto risco sanitário, 
havendo, portanto, no conjunto das creches estudadas, um atendimento parcial à legislação vigente.

É necessário, portanto, uma adequação das creches avaliadas, à RDC n²16 de 15/09/2004 da ANVISA, e uma intervenção imediata para que haja uma melhor segurança dos alimentos que estão sendo produzidos e uma proteção contra surtos alimentares.

$$
\text { Considerando as dificuldades }
$$

identificadas, e as possibilidades de resolvêlas mediante planejamento a curto e a longo prazo, faz-se necessária uma fiscalização mais rigorosa pelos órgãos públicos competentes para promover e garantir a segurança alimentar e nutricional da população infantil.

\section{REFERÊNCIAS}

ANDRADE, I.C.A. Avaliação das condições higienico-sanitárias das unidades de alimentação das escolas públicas do município de Igarassu - PE e adequação a RDC 216. In: Congresso de Economia doméstica, 20.; 2009, Fortaleza-CE. Anais, Fortaleza: UFC, 2009. 7p.

\section{ANVISA. Cartilha sobre Boas Práticas} para Serviços de Alimentação - Resolução n²16/2004. Disponível em: <www.anvisa.gov.br>. Acesso em: $15 \mathrm{fev}$. 2014.

BASTOS, C.C. B. Condições higiênicosanitárias no preparo de refeições em creches comunitárias de Belo Horizonte, Minas Gerais. 2008 112f. Dissertação (Mestrado em Ciências de Alimentos) - Faculdade de Farmácia, Universidade Federal de Minas Gerais, Belo Horizonte, 2008.
BRASIL. Agência Nacional de Vigilância Sanitária. Resolução RDC n 216, de 15 de setembro de 2004a. Dispõe sobre regulamento técnico de Boas Práticas para serviços de alimentação. Diário Oficial da República Federativa do Brasil, Brasília, DF, 16 set. 2004. Disponível em: < http://elegis.anvisa.gov.br/leisref/public/show Act.php?id=1254 6>. Acesso em: 26 mar. 2014.

\section{BRASIL. Ministério da Educação e do}

Desporto. Subsídios para elaboração de diretrizes e normas para a educação infantil, 1998.

BRASIL. Ministério da Saúde. Resolução RDC nº 275, de 21 de outubro de 2002. Dispõe sobre regulamento técnico de Procedimentos operacionais padronizados aplicados aos estabelecimentos produtores/industrializadores de alimentos e a lista de verificação das boas práticas de fabricação em estabelecimentos produtores/ industrializadores de alimentos. Diário Oficial da República Federativa do Brasil, Brasília, DF, 06 de nov. de 2002, Seção 1, p. 4-21

CARDOSO, R.C.V.; SOUZA, E.V.A.; SANTOS, P.Q. Unidades de alimentação e nutrição nos campi da Universidade Federal da Bahia: um estudo sob a perspectiva do alimento seguro. Rev de Nutrição, v. 18, n.5, p. 669-680, 2005.

FAÇANHA, S. H. F. et al.Treinamento para manipuladores de alimentos, em escolas da rede municipal de ensino, da sede e distritos do município de Meruoca, Ceará: relato de experiência. Hig Aliment, v.17, n.106, p.3034, 2003.

GENTA, T. M. S.; MAURÍCIO, A. A.; MATIOLI, G. Avaliação das Boas Práticas através de check-list aplicado em restaurantes self-service da região central de Maringá, Estado do Paraná. Acta Sci. Health Sci, v.27, n.2, p.151-156, 2005. 
GÓES, et al. Capacitação dos manipuladores de alimentos e a qualidade da alimentação servida. Rev Hig Aliment, v. 15, n. 82, p. 2022, 2004.

GRAMULHA, et al. Boas Práticas de Fabricação: Enfoque na importância do treinamento de manipuladores, 2006.Disponível em: <www.nutrinews.com.br>. Acesso em: 15 jul. 2014.

ICMSF (International Commission on Microbiologycal Specifications for Food). El sistema de análisis de riesgos y puntos críticos: Su aplicación a las industrias de alimentos. Zaragoza: Acribia, 1991, 989p.

INSTITUTO NACIONAL DE ESTUDOS E PESQUISAS EDUCACIONAIS ANÍSIO TEIXEIRA. Censo revela crescimento no ensino integral, Disponível em : $<$ http://portal.inep.gov.br/visualizar//asset_publisher/6AhJ/content/censo-revelacrescimento-no-ensino-integral $>$ acesso em 15 de ago. 2014.

KAPPEL, M. D. B; CARVALHO, M. C; KRAMER, S. Perfil das crianças de 0 a 6 anos que freqüentam creches, pré-escolas e escolas: uma análise dos resultados da Pesquisa sobre Padrões de Vida/IBGE. Rev Bras de Educ, n. 16, p. 35-47, 2001.

\section{LIMA, R, C. Quem está na minha cozinha?} São Paulo: Livraria Varella, 2001.

NEZI, F. Avaliação da aplicação dos POP's em uma unidade de Alimentação e nutrição através da verificação de análises Microbiológicas. 2008. 13f. Monografia (Bacharel em Nutrição) - Faculdade Assis Gurgacz, Cascavel, 2008.

OLIVEIRA et al., Condições higiênicosanitárias do comércio de alimentos no município de Ouro Preto, MG. Revista Higiene Alimentar. São Paulo. v.19, n.136, p.26-31, 2005.
OLIVEIRA, et al. Manipulador de alimentos: um fator de risco. Revista Higiene Alimentar, São Paulo, v. 17, n. 115, p. 13-19, 2004.

OLIVEIRA, M. N.; BRASIL, A. L. D.; TADDEI, J. A. A. C. Avaliação das condições higiênico-sanitárias das cozinhas de creches públicas e filantrópicas . Rev Ciênc Saúde Coletiva, v.13, n.3, p.10511060, 2008.

RICHARDS et al. Investigation of a staphylococcal food poisoning outbreak in a centralized school lunch program. Public Health Rep, v. 108, n. 6, p.765-771,1993.

ROCHA, B. et al. Avaliação das condições higiênico-sanitárias e da temperatura das refeições servidas em restaurantes comerciais do tipo self-service. Revista do Núcleo Interdisciplinar de Pesquisa e Extensão do UNIPAM, v.1, n. 7, p. 30-40, 2010.

ROSSI, C.F. Condições higiênico-sanitárias de restaurantes comerciais do tipo selfservice de Belo Horizonte - MG. 2006. 142f. Dissertação (Mestre em ciências de alimentos) - Faculdade de Farmácia, Universidade Federal de Minas Gerais, Belo Horizonte, 2006.

SEIXAS, F. R. F. et al.Check-list para diagnóstico inicial das Boas Práticas de Fabricação (BPF) em estabelecimentos produtores de alimentos da cidade de São José do Rio Preto (SP). Revista Analytica, n. 33, p. 36-41, 2008.

SILVA JR, E.A. Manual de Controle Higiênico-Sanitário em Serviço de Alimentação. São Paulo: Livraria Varela. 6 ed. 2005. 214p.

SOUZA, L. H. L. A manipulação inadequada dos alimentos: fator de contaminação. Hig. Aliment., v. 20, n. 146, p. 32-39, 2006.

TURATTI, M.S.; PESSOLATO, A.G.T.; SILVA, M.M. A importância da afetividade na educação da criança. Rev. da Univ. Vale do Rio Verde, v. 9, n. 2, p. 129-142, 2011. 
VALEJO, F.A.M. et al. Vigilância Sanitária: Avaliação e Controle da Qualidade dos

Alimentos. Higiene Alimentar, v. 17, n. 106, p. 16-21, 2003.
VEIGA, C. F. et al. Estudo das condições sanitárias dos estabelecimentos comerciais de manipulação de alimentos do município de Maringá, PR. Rev Hig Aliment, São Paulo, v. 20, n. 138, p. 28-35, 2006. 